\title{
Cartografía cultural. Algunos apuntes y reflexiones
}

\author{
Cultural cartography. Notes and reflections
}

\section{Mariana Wainstein*}

\footnotetext{
* Consultora en gestión cultural. Departamento de Cultura, Intendencia Departamental de Treinta y Tres, Uruguay.

$\triangle$ emedobleve@gmail.com https://orcid.org/0000-00019445-4836
}

\section{Resumen}

Una rápida mirada a la situación de las políticas culturales en Uruguay desde una perspectiva de crítica constructiva. Reflexiones sobre el rol del Estado, la necesidad de un sinceramiento del mapa cultural que se presenta y la importancia de asumir liderazgos y tomar decisiones.

Palabras clave: Estado, política cultural, Uruguay.

\section{Abstract}

A quick glance at the situation of cultural policies in Uruguay, from a perspective of constructive criticism. Reflections on the role of the State, the need for a more truthful cultural map and the importance of assuming leadership and making decisions.

Keywords: State, cultural policy, Uruguay.

Omnis determinatio est negatio.

Baruch Spinoza

\section{Mapas}

En la obra El cartógrafo, de Juan Mayorga, un anciano le habla a una niña sobre el arte de la cartografía (Mayorga, 2017). 
Anciano -El mal cartógrafo quiere ponerlo todo. Si lo pones todo, nadie verá nada. Te lo he explicado mil veces: «Definitio...».

Niña - «Definitio est negatio».

Anciano - Sacrificar: eso es lo más importante al hacer un mapa. ¿Qué quiero hacer visible? Si tengo eso claro, sabré qué dejar fuera. «Definitio est negatio».

A la hora de observar y de reflexionar acerca de políticas culturales, el concepto expuesto por Mayorga (2017) puede resultar útil y posiblemente necesario. El mapa que aparece hoy día ante nuestra vista se halla sobrecargado de indicaciones y símbolos. En vez de perderse en enumeraciones, acaso correspondería establecer lo que realmente es necesario que el mapa muestre. Muchas de las señales que aparecen resultan por demás significativas, pero otras, sin embargo, no pasarían de ser vacíos gestuales.

Ese es el primer desafío del cartógrafo: definir cuáles son las señales sustantivas que deben estar en el mapa y cuáles fueron puestas como relleno para dar sensación de una actividad frenética y trascendente que en los hechos nunca pasó de hueras intenciones, como si la mera enunciación de las cosas hiciera que las cosas fueran.

La primera pregunta que nos asalta al mirar el sitio web de la Dirección Nacional de Cultura (DNC) es: ¿Por qué un mapa tan sobrecargado? ¿Realmente la actividad desarrollada lo justifica? ¿Es que acaso todas las actividades que se enumeran han tenido la misma jerarquía, han dado indicadores exitosos, se han llevado a cabo en los hechos? ¿Es que han mejorado el acceso de la población a los bienes culturales, han logrado desarrollar audiencias, despertar un mayor interés objetivo de la población por la actividad cultural de toda índole? ¿Hay estudios al respecto? Asimismo, ¿se han monitoreado los resultados de las políticas culturales adoptadas y sus efectos? (y con este término se hace referencia a monitoreos externos, serios y totalmente independientes de las instituciones responsables de crear y llevar adelante las políticas).

Paralelamente, se percibe una tendencia a la debilidad institucional, fundamentalmente en la DNC, donde la mayor parte de los funcionarios, mal remunerados, se muestran en actitud de permanente insumisión y protesta, y su actividad o no actividad se traduce en una rémora constante y en un resentimiento hacia la propia institución que representan.

A lo dicho se suma que, en el ambiente artístico, los agentes culturales quieren más. Todos aspiran a recibir un apoyo como el que recibe el Ballet del Sodre. Se reclama que el artista pueda vivir de su actividad, como cualquier otro trabajador. Todo esto obviamente es muy justo, pero exige recursos, planificación y toma de decisiones que se han venido eludiendo en los últimos tiempos. El artista siempre está ávido de subsidios. La cuestión es si el país puede y quiere pagarlos, y hasta dónde. 
En el mapa no se puede señalar como altas cumbres lo que no pasa de cerros chatos, ni como ríos caudalosos los arroyos cuyos cauces están secos buena parte del año. Tampoco se puede presentar como gestores culturales a personas cuyas únicas credenciales son algún tipo de autoproclamada experiencia en el ramo cultural o el hecho de ser artistas, lo cual no los convierte en gestores. Por el contrario, en el mundo, y cada día más, la gestión cultural suele ser materia de profesionales, porque las grandes instituciones culturales comprendieron que aun los mayores artistas suelen ser pésimos gestores si no tienen formación específica en la materia.

A eso hay que agregar lo atinente a los cargos de particular confianza, muchas veces provistos con personas que no son ni artistas ni gestores culturales, pero que por razones discrecionales del gobierno de turno terminan acaparando importantes responsabilidades sin tener la aptitud ni la actitud necesarias. En muchos casos son personas que aceptan esas designaciones como quien recibe una dádiva a cambio de algo, pero sin entender la exigencia que conlleva desempeñar un cargo público, ni el compromiso trascendente con el país y la sociedad que la cultura demanda. Algunos suponíamos que las situaciones de este tipo estarían superadas, dado que una de las principales promesas del progresismo fue echar por tierra el clientelismo y, en cambio, fomentar la meritocracia. Está claro que la desafección de la población respecto a la política es un resultado de este tipo de conductas, en este caso relacionadas con lo cultural.

Nos hallamos ante un verdadero cambio de paradigma en materia cultural. Ante ello, ¿basta hacer algunos cambios cosméticos en el mapa, basta simplemente alivianarlo, o es hora de dibujar un mapa nuevo?

\section{El rol del Estado}

Anciano -Dibujado con todo detalle. Este mapa no dice nada sobre el mundo, pero lo dice todo sobre el mundo para el que fue dibujado. En cada mapa está el mundo que lo dibujó.

Niña - ¿Hay algún orden?

Anciano -Lo hay, pero tienes que encontrarlo tú. (Mayorga, 2017)

El primer aspecto que debería definirse sería el rol del Estado. En el mundo de las ideas vemos que este aspecto oscila entre la visión del liberalismo puro, en esa región donde casi se roza con el anarquismo, al plantear una ausencia total del Estado, y en el otro extremo la premisa máxima y característica de los regímenes totalitarios, en los cuales todo es Estado y nada puede desarrollarse por fuera de él. Es evidente que la solución debería buscarse en un plano intermedio. 
Hoy día estamos ante una presencia un tanto exacerbada del Estado en la cultura, herencia acaso del ADN batllista del Uruguay, donde todo se espera del Estado como si este fuese un demiurgo capaz de atender cualquier tipo de necesidad ipso facto.

Posiblemente sea hora de plantearnos cuál sería ese punto en que el Estado debería situarse para no transformarse en curador y mediador de todos los procesos que integran la actividad cultural.

En esta cuestión hay aspectos claramente esenciales para un país democrático. Lo primero que tiene que hacer el Estado en el campo cultural es ser un garante absoluto de la libertad de expresión, asegurando que en esta materia no haya ideologías dominantes y que todos los creadores puedan expresarse en sus diferentes disciplinas y lenguajes, como forma de evitar la existencia de un pensamiento hegemónico y fortalecer la diversidad.

El segundo aspecto irrenunciable es fomentar que la ciudadanía en general se involucre en la cultura, que los ciudadanos se integren en los espacios culturales, que asuman responsabilidades, que puedan hacer propuestas y llevar adelante proyectos como sociedad civil.

El tercer aspecto es el cuidado del patrimonio nacional, tangible e intangible. Y el cuarto debería ser sostener, tanto en los aspectos edilicios como de equipamiento, las infraestructuras necesarias para que el encuentro artístico ocurra, eventualmente en asociación con el sector privado.

Hasta aquí los cuatro aspectos esenciales del mapa.

Podríamos agregar como aspecto significativo el apoyo del Estado a la formación y capacitación básica y avanzada de los oficios cercanos a la actividad artística, como forma de unir la actividad creativa con el relevante tema de la educación en relación con el desarrollo y la creación de empleo.

En igual sentido resultaría importante el apoyo a proyectos culturales ligados al desarrollo social y económico; bibliotecas, centros culturales, usinas culturales que puedan contribuir a mejorar las condiciones de vida y las oportunidades en lugares carenciados o con problemáticas complejas. Como ejemplo interesante fuera de fronteras aparece el caso de Colombia, donde la actividad cultural tuvo influencia directa en los procesos de pacificación y de alejamiento de la población —especialmente de la población más joven- de actividades delictivas relacionadas con el mundo de la droga y el narcotráfico. Creemos que sigue habiendo hay un amplio espacio en Uruguay —más allá de los esfuerzos realizados, que mucho se reconocen- para continuar invirtiendo en aspectos ligados a la cultura y a las artes como factores integradores y estimuladores de la sociedad en su conjunto.

Otro aspecto en el que sería conveniente profundizar es el de direccionar fondos para que los artistas puedan seguir recibiendo el apoyo del sector privado interesado 
en proveerlos, tanto hacia el interior como hacia el exterior del país. No se trata de fomentar que el sector privado aporte fondos a la cultura solo para recibir exoneración fiscal, sino de conseguir, como en otros países, un cambio de mentalidad que lleve a que el sector privado - especialmente el empresarial - se sienta integrado y comprometido con la cultura.

Estos últimos puntos no pretenden ser una enumeración exhaustiva de los aspectos en los cuales el Estado puede estar presente. Se plantean a modo de ejemplo, como aspectos relevantes a tener en cuenta.

\section{Conectando mapas}

Diseñar un mapa de estas características resulta asimismo una oportunidad de tener en cuenta los objetivos de desarrollo sostenible planteados por las Naciones Unidas (ONU, s/f), así como también la Declaración Universal sobre Diversidad Cultural (UNESCO, 2004) y la Carta Cultural Iberoamericana (2006).

Dado que se trata de compromisos internacionales asumidos por Uruguay, el gobierno debería continuar invirtiendo en consolidar diferentes aspectos de la llamada economía naranja, término que refiere a la complementación entre economía y cultura y, más específicamente, al desarrollo económico que involucra a las industrias creativas (Buitrago y Duque, 2013).

\section{Institucionalidad}

¿Dónde están los hombres? Este mapa de lenguas, este de credos, este de razas, preparan ataques que borrarán fronteras; son armas contra otros mapas. En la mesa de los poderosos siempre hay mapas. Mapas que exhiben para asustar y mapas secretos que jamás muestran. Mapas nuevos llenos de delirios y mapas viejos que empuñarán para llamar a la guerra.

¡Cuántas catástrofes han comenzado en un mapa! Buenos tiempos para el cartógrafo, tiempos difíciles para la humanidad.

Niña - $i$ «Retroceso de los bosques europeos»?

Anciano -En realidad, son tres mapas: 1800, 1850, 1900. Es lo más difícil de representar, y lo más importante: el tiempo. Lo más importante del espacio es el tiempo. Europa 1914; Europa 1918. ¡El tiempo! 
La creación de la unidad ejecutora DNC el 1 de enero de 2008 con un presupuesto propio y la gestión de buenas ideas marcaron en su momento un antes y un después en el desarrollo de la institucionalidad de la actividad cultural uruguaya. En aquellos primeros años se podía apreciar un claro entusiasmo y un liderazgo en materia de ideas e iniciativas. No fue solamente conseguir un presupuesto, sino que en cada acción había toma de decisiones y visión de futuro. Es de destacar la creación y organización de fondos concursables, de apoyo a la infraestructura, de incentivo cultural, así como también la creación del Instituto del Cine y el Audiovisual y del Instituto Nacional de Artes Escénicas como articuladores de políticas y actividades específicas.

Luego lamentablemente se percibe un estancamiento. En toda actividad humana el continuo pensar y accionar para mantener y mejorar lo logrado, así como la búsqueda de nuevos y mejores objetivos, resulta fundamental para no caer en un deterioro. Ni que hablar en materia cultural. No debemos permitir que la entropía lleve a transformar el sistema en un mero enunciado de continuas expresiones de deseos y gestualidad vacía.

\section{Centros MEC: Buena idea. ¿Deterioro de la gestión?}

Sorprende lo desdibujada que aparece actualmente la gran idea de ganarles a las malas carreteras uruguayas llevando al MEC a todos los rincones. Los Centros MEC fueron una idea maravillosa y absolutamente necesaria para el país, pero hoy impacta enterarse de que inexplicablemente se han independizado de la DNC, cuando estaban llamados a ser una extensión territorial de ella. Lo sucedido supone una duplicación de tareas y de gastos, además de traslucir una falta de coordinación inadmisible, como si la actividad que desarrollan los centros MEC fuera diferente a la de la DNC. Leo trabajos académicos que enumeran actividades de los Centros MEC y no coinciden con la actividad que percibo en el campo. Puedo estar equivocada, pero vuelvo a pensar en el sinceramiento del mapa.

Actualmente existen 125 Centros MEC distribuidos en los 19 departamentos de Uruguay. En el período 2010-2014, más de 1.300.000 personas participaron en actividades realizadas por Centros MEC; se realizaron 3.401 cursos, talleres y charlas, 557 exposiciones, 1.928 espectáculos musicales, 1.229 espectáculos de artes escénicas, 1.589 proyecciones audiovisuales, 867 actividades recreativas y otras. (Alonso, Delgado y Traverso, 2015)

A propósito, es recomendable la lectura del capítulo 9 del libro citado, donde Alonso, Delgado y Traverso reflexionan sobre la calidad del sistema de evaluación de políticas culturales y hasta sugieren indicadores para el caso de los CMEC. Los restantes 
capítulos de este libro conforman una celebración de los Centros MEC como ejemplo de innovación en la gestión pública de alcances épicos. En varios de los artículos se repite el relato del origen de los Centros y de lo singular de sus propuestas y su operativa. El ministro de la época llega a escribir en el prólogo: «Quien escribe estas líneas se siente con la libertad de afirmar, habiendo estado ajeno al comienzo de la iniciativa, que se trata de una propuesta cuyo carácter podría llamarse virtuoso» (Ehrlich, 2015).

Sin embargo, a esta altura cabe preguntarse cuál es la participación real de los Centros MEC en el desarrollo de la política cultural del país. ¿De la enorme cantidad de actividades que se señalan correspondería inferir que en todos los casos tuvieron la iniciativa, tuvieron a su cargo la organización, dieron algún tipo de apoyo de cualquier tipo, o se está contabilizando en el mismo nivel gran cantidad de actividades en las cuales se limitaron a asistir al acto de inauguración? Si realmente, como dice el informe, en el período 2010-2014 los CMEC realizaron 1.928 espectáculos musicales y 1.229 espectáculos de artes escénicas, deberíamos concluir que son el productor más importante del país. ¿Realmente es así?

Este tema daría pie para muchas reflexiones y comentarios que excederían el presente artículo. Lo más importante que queda es preguntarnos dónde estamos al día de hoy en la batalla de la descentralización, si realmente avanzamos y cómo deberíamos hacer las evaluaciones del caso.

\section{Fondos de Incentivo Cultural: Iniciativa exitosa. ¿Falta de puesta al día?}

Otro hito que merece atención es el de los Fondos de Incentivo Cultural. A pesar de los resquemores que provocaron en su momento, su consolidación y un prestigio bien ganado muestran que la filosofía que marcó su creación iba en la dirección correcta. Paso a paso las empresas comprendieron el mecanismo, y el espacio fiscal cedido por el Estado empezó a ser utilizado con fluidez. A ello contribuyeron la ampliación del consejo —que integró la representación del sector privado-, una buena política de comunicación y una buena administración del sistema, que cada vez tuvo que gestionar más y mayores proyectos ingresados.

Sin embargo, se advierte que el sistema, que a esta altura debería ser un mecanismo aceitado para permitir el encuentro y la cooperación entre el sector empresarial y el sector artístico, se mantiene anquilosado en la estructura original, que no se adapta a las nuevas demandas. Tal vez lo más importante en este sentido sería agilizar el proceso manteniendo el espíritu garantista que el Estado provee. 
Habría que concentrarse en el contralor financiero y la transparencia de la ejecución de los proyectos y dejar que los aspectos culturales fluyan libremente. Vale decir, ¿es necesario que haya tribunales juzgando proyectos durante tres meses? ¿Por qué siempre ese énfasis curatorial del Estado? ¿Quién determina qué está bien o qué está mal? De paso, nos ahorraríamos los miles de dólares que el mecanismo invierte en pagar a los miembros de la decena de tribunales constituidos como filtros insalvables para cientos de proyectos.

\section{Mapa del interior}

En el resumen analítico Indicadores UNESCO de cultura para el desarrollo (UNESCO, 2014) se señala:

En lo que respecta a la descentralización de la gobernabilidad de la cultura, desde el año 2012 Uruguay cuenta con una Red de Directores de Cultura Departamental para fomentar el diálogo e intercambio horizontal en las Direcciones de Cultura. Sin embargo, no hay instituciones especializadas o responsables de la cultura a nivel local/municipal de la administración pública. Si bien en general los resultados de este indicador son muy positivos y reflejan las muchas instituciones formales, políticas y mecanismos establecidos en el Uruguay, una investigación adicional resulta necesaria para ir más allá y evaluar el impacto efectivo de la política nacional, del marco institucional para la cultura y la traducción de las palabras en acción y resultados.

Si partimos de la base de que todo gobierno uruguayo, sea del signo que sea, tiene como desafío evidente combatir la macrocefalia capitalina para darle unidad y coherencia a todo el país, el vehículo de la cultura es una herramienta fundamental en ese proceso. No corresponde a un gobierno inventar la parte creativa o sembrar agentes culturales donde no los hay, pero sí establecer una metodología de trabajo que se dedique al fomento de la cultura, a la circulación cultural efectiva y no a una mera enunciación.

¿Cuál es hoy el sistema que permite que las autoridades locales de los departamentos accedan a un presupuesto nacional con el tiempo suficiente para planificar? ¿Hasta cuándo este proceso seguirá basándose en la negociación personal con las autoridades de turno residentes en Montevideo en cada ocasión en que se requiera apoyo?

En lo que refiere al establecimiento de un plan nacional de cultura, ¿cuáles son claramente los mecanismos por los cuales ese plan se desarrolla y cómo se contempla la inclusión auténtica del interior como parte activa? ¿Cuándo termina el diagnóstico 
que supuestamente se está haciendo desde hace varios años y cuándo comienza la acción? El interior está siendo tratado como un receptor pasivo que debe negociar cada día la dosis de apoyo que las autoridades de Montevideo entiendan apropiada. Aun cuando no sea la intención, esto tiende a despertar suspicacias políticas sobre por qué se apoya más a un departamento que a otro. Tampoco se trata de hacer una mera suma aritmética de cuánto se aportó en recursos ni de elaborar una fría estadística, sino de analizar la calidad real del apoyo e incluso de establecer un monitoreo adecuado para el análisis de impactos y resultados, en el cual estén involucradas tanto las autoridades nacionales como las departamentales.

\section{Readecuación de escala}

Vivimos en un mundo mediatizado, donde la tentación de comunicar supuestos logros es grande, pero el Estado debe mantener una austeridad republicana también en ese aspecto. El Estado no es una empresa que debe estar continuamente promocionando su producto.

Sinceremos el mapa. Dejemos lo que importa y lo que podemos realmente hacer bien, sin falsos mensajes ni rellenos. Es indudable que los proyectos culturales son infinitos y los recursos son finitos, pero por lo menos administremos mejor lo que tenemos, optimicemos la gestión, asumamos la toma de decisiones, incentivemos al sector empresarial y a la sociedad civil a formar parte de la actividad cultural.

Los planteos que aquí se formulan no suponen acrecentar las erogaciones del Estado en materia de cultura, sino mejorar la gestión para que los recursos con los cuales se cuenta puedan tener el mejor efecto. Revisemos cuánto se llevan del presupuesto cultural el mantenimiento de una burocracia en muchos casos ociosa e ineficiente - tanto nacional como departamental-, los proyectos obsoletos o innecesarios.

Dejemos un equipo reducido y dignamente remunerado para llevar adelante la gestión de los grandes proyectos necesarios para hacer la diferencia en materia de desarrollo cultural. Imaginemos un mapa con una eficiente coordinación de fondos, acciones para mejorar la infraestructura a escala nacional, cuidar el patrimonio y relacionarlo con aspectos de educación, turismo cultural y desarrollo.

Recordemos que, vengamos de donde vengamos — de izquierda, de centro o de derecha, estatistas o liberales-, los que realmente amamos la cultura y la sentimos como la razón de ser, lo que nos define como seres humanos, estamos de forma transversal espiritualmente unidos en una especie de Partido virtual de la Cultura, que es por otra parte el único elemento en el cual Uruguay no tiene por qué cederle la derecha a nadie, dado que es un campo en el cual ha obtenido relevantes conquistas y se ha ganado un bien merecido sitial en el mundo. Eso debemos defenderlo y acrecentarlo. 


\section{Referencias bibliográficas}

Alonso, J., Delgado, P. y Traverso, D. (2015). «Hacia la evaluación de política pública en cultura». En L. Caldés y S. Guerrero (coords.), X125 Centros mec en el territorio. Montevideo: mec. Recuperado de http://www.centrosmec.org.uy/libro/capitulo09.html.

Buitrago, F. y Duque, I. (2013). La economía naranja: Una oportunidad infinita. Washington: BID. Recuperado de https://publications.iadb.org/bitstream/ handle/11319/3659/La\%20economia\%20naranja\%3a\%20Una\%20oportunidad $\% 20$ infinita.pdf?sequence $=4$.

Carta Cultural Iberoamericana (2006). Recuperado de http://segib.org/wp-content/uploads/Carta-cultural-iberoamericana.pdf.

Ehrlich, R. (2015). «Prólogo». En L. Caldés y S. Guerrero (coords.), X125 Centros mec en el territorio. Montevideo: mec. Recuperado de http://www.centrosmec. org.uy/libro/prologo.html.

Mayorga, J. (2017). El cartógrafo. Madrid: Uña Rota.

ONU (s. f.) Objetivos de desarrollo sostenible de Naciones Unidas: 17 objetivos para transformar nuestro mundo. Recuperado de http://www.un.org/ sustainabledevelopment/es/objetivos-de-desarrollo-sostenible/.

Unesco (2004). Declaración Universal sobre la Diversidad Cultural: Una visión, una plataforma, conceptual, un semillero de ideas, un paradigma nuevo. Lima: unesco. (Serie sobre Diversidad Cultural, 1). Recuperado de http:// unesdoc.unesco.org/images/0012/001271/127162s.pdf.

Unesco (2014). Indicadores unesco de cultura para el desarrollo: Resumen analítico de Uruguay. Recuperado de http://es.unesco.org/creativity/sites/creativity/files/ cdis/resumen_analitico_iucd_-_uruguay_1.pdf 